\title{
A UTILIZAÇÃO DO LAPTOP EDUCACIONAL NA CONTAÇÃO DE HISTÓRIAS
}

\author{
Maria Bernadete Melo de Oriá ${ }^{1}$, Ellen Lacerda Carvalho Bezerra ${ }^{2}$, José Aires \\ Castro Filho $^{3}$ \\ ${ }^{1} e^{2}$ Faculdade de Educação/ Universidade Federal do Ceará (UFC) \\ Rua Marechal Deodoro, 750 - Benfica, Fortaleza - CE, 60020-060 \\ ${ }^{3}$ Instituto UFC Virtual. Universidade Federal do Ceará (UFC) \\ Campus do Pici, bloco 901, $1^{\circ}$ andar, CEP: 60.455-760 \\ ${ }^{1} \mathrm{e}^{3}\{$ berna, aires $\} @$ virtual.ufc.br \\ 2 ellen.lcb7@gmail.com
}

\begin{abstract}
The storytelling gives emotions through illustrations and details that transport often the listener within the narrated story. In this context, this study shows an experience report of a pedagogical action with the use of digital technologies as a resource in the creation and storytelling held in Elementary Education segment in the 4th and 5th years, involving a total 125 students. The project was developed in stages ranging from the planning of activities to be performed, the choice of content, methodology of work, internet research, interviews, performances, writing stories and illustrated scenarios record of productions, creation of collective texts, finalized with the preparation of the book of short stories and published. Based on these actions, we focus on the entire development of the project as well as its conclusion and culmination.
\end{abstract}

Key-words: storytelling, digital technologies, educational laptop.

Resumo. A contação de história proporciona emoções por meio de ilustrações e detalhes que transportam, muitas vezes, o ouvinte para dentro da própria história narrada. Dentro desse contexto, este estudo mostra um relato de experiência de uma ação pedagógica com o uso das tecnologias digitais como recurso na criação e contação de história, realizado no seguimento do Ensino Fundamental nos $4^{\circ}$ e $5^{\circ}$ anos, envolvendo um total 125 alunos. O projeto foi desenvolvido em etapas que vão desde o planejamento das atividades a serem realizadas, escolha dos conteúdos, metodologia de trabalho, pesquisa na Internet, entrevistas, encenações, elaboração de histórias e de cenários ilustrados, registro das produções, criação de textos coletivos, finalizado com a elaboração do livro de contos e sua publicação. Partindo destas ações, enfocaremos todo o desenvolvimento do projeto, bem como sua conclusão e culminância. Palavras- chaves: contação de história, tecnologias digitais, laptop educacional.

\section{Introdução}

Contar histórias é uma prática antiga, que permite aos ouvintes, principalmente às crianças, a oportunidade de desenvolver a autonomia do pensamento. Os contos de fadas, por exemplo, podem, além de promover o gosto pela leitura, levar os ouvintes a fazerem uma viagem pelo caminho do imaginário. Ao construir e ao entender o "faz de conta", o leitor pode imergir-se no lúdico e na fantasia. A contação de história também proporciona emoções por meio de ilustrações e detalhes que podem levar o leitor a criar, a contar suas próprias narrativas e a imaginar situações em que ele próprio aparece como personagem na história. 
Os contos podem conter som, imagem, texto, hipertexto, vídeos, animações, simulações e desenhos. Dessa forma, amplia a possibilidade da criança usar sua imaginação para comunicar-se com seus pares. O leitor pode inventar novos finais para cada texto interativo lido, criar novos cenários, outros personagens e narrativas colaborativas.

Sob essa análise, a Internet também é mais um ambiente de acesso à leitura. Há sites que já disponibilizam versões de livros incluindo os contos infantis em formato digital. Novos horizontes surgem para o mundo da leitura dos contos para crianças. Na perspectiva de Lévy (1996), a literatura infantil ganhou espaço no mundo digital devido a dois fatores, primeiro, à motivação pela leitura que o ambiente virtual propõe e segundo ao fato de as crianças, na atualidade, estarem inseridas desde cedo no contexto da virtualidade.

Acerca da relação da Literatura Infantil e as tecnologias, Cunha (2010, p.35) afirma:

\footnotetext{
"Para procedermos à discussão a respeito do livro, da leitura, da literatura e sua relação com a escola e a tecnologia, temos que atravessar uma brecha: em primeiro lugar reconhecer que com a introdução da escrita nos meios eletrônicos, emergem novas formas de leitura [...] evidentemente ler sobre uma tela não é ler um códex". (CUNHA, 2010, p. 35)
}

A autora faz uma ligação entre a literatura infantil e a tecnologia, uma vez que estamos na era digital, e a escrita se insere nesse meio como uma importante possibilidade, ampliada pelo possível uso dos diversos recursos tecnológicos disponíveis.

Nesse sentido, o presente escrito foca uma experiência de contação e criação de histórias, mediada pela tecnologia. Estudantes do $4^{\circ}$ e $5^{\circ}$ ano do Ensino Fundamental utilizaram aplicativos computacionais para a construção de cenários ilustrados, produção textual compartilhada, além da Internet para a realização de leituras, pesquisas e a criação de portfólios digitais para publicação dos trabalhos no blog da escola. A ação teve duração de dois meses, incluindo planejamento, desenvolvimento e socialização do projeto na escola. Ao final do trabalho, foi desenvolvido um livro de contos impressos. 
CBIE-LACLO 2015

Anais do XXI Workshop de Informática na Escola (WIE 2015)

\section{Percurso Teórico}

Na perspectiva de Chartier (1994), a materialidade do livro foi alternada e complementada pela imaterialidade de textos sem lugar específico; às relações de contiguidade estabelecidas no objeto impresso opõe-se a livre composição de fragmentos infinitamente manipuláveis - são textos móveis que se dobram e se desdobram à vontade diante do leitor. Com a desmaterialização do texto eletrônico, vamos ter um suporte dinâmico que distribui textos online, que nos permite ter uma grande biblioteca sem muros.

Na perspectiva de Sobreira et al (2013), a produção de histórias não lineares com os recursos tecnológicos enriqueceram todo o trabalho, desde o desenvolvimento das pesquisas, até a finalização, com a digitação do texto, a produção das ilustrações digitais, a criação das opções "interativas" e a publicação do resultado final.

Lima e Castro (2009) desenvolveram o projeto cujo objetivo foi propor aos alunos a produção de gifs animados referentes ao tema do meio ambiente, tomando como base a criação de histórias em quadrinhos. Por conclusão, ficou evidenciado que o uso de diferentes ferramentas computacionais aprimora o estudo dos conteúdos curriculares. Em consonância com a experiência relatada neste artigo, concluímos a importância do uso dos recursos digitais para integrar ao desenho curricular da escola, auxiliando na aprendizagem dos alunos, e neste o caso, na produção textual dos alunos.

\subsection{A Leitura e a Escrita}

Podemos perceber que, antes da escrita, os saberes da humanidade eram transmitidos por meio das narrativas e, com o passar do tempo, à medida que o falar se tornou insuficiente para expressar e manifestar a cultura de uma sociedade, o homem começou a pensar em materiais palpáveis que organizassem o conhecimento adquirido, isto é, a escrita. 
CBIE-LACLO 2015

Anais do XXI Workshop de Informática na Escola (WIE 2015)

Os contadores de histórias da antiguidade utilizavam basicamente o recurso da palavra, reunindo ouvintes que se identificavam e encantavam-se com suas sábias narrativas. No entendimento de Busatto (2003),

“[...] o conto de literatura oral se perpetuou na História da humanidade através da voz dos contadores de histórias, até o dia em que antropólogos, folcloristas, historiadores, literatos, linguistas e outros entusiastas do imaginário popular saíram a campo para coletar e registrar estes contos, fosse através da escrita ou outras tecnologias."

Nesse sentido, as crianças, quando escutam histórias, tendem a vivenciar o enredo, incorporando a figura das personagens. Por meio do estímulo da imaginação, interpretam o que ouvem, realizam trocas lúdicas com seus pares e permutam vivências e saberes, tudo isso por meio da leitura. Assim, é importante que a formação das crianças no âmbito literário comece na infância. A escola, neste caso, assim como a tecnologia, torna-se uma grande aliada neste processo de leitura.

O presente trabalho foi estruturado para que os recursos tecnológicos fossem agregados a esses momentos de contação de histórias e pudessem trazer aparatos, concepções relevantes a essa prática. Juntou-se a prática da escrita aos recursos digitais com o intuito de proporcionar aos alunos uma maior ludicidade para enredos criados. Dentro desse contexto, propomos que a contação de histórias se apresente de maneira lúdica, renovada, despertando ainda mais o interesse dos pequenos leitores para esta prática.

\section{O Projeto}

O projeto de Criação de Histórias intitulado "Ai que medo! Com o uquinha também posso me arrepiar" foi elaborado pelos professores de Português, Matemática e Artes juntamente com a coordenação pedagógica da escola e os integrantes do grupo de formação esta ação é fruto de uma prática planejada na escola, vinculada ao currículo na utilização do laptop educacional.

A formação de professores na escola foi desenvolvida em processo contínuo, em que a apropriação dos diversos recursos tecnológicos foi intercalada com momentos de utilização de tais instrumentos em práticas com alunos, nos trabalhos 
coletivos da escola, nas aulas, na utilização do laptop como ferramenta, com reflexões e registros dos processos e resultados, tendo como base as teorias sobre o uso das tecnologias digitais na educação.

A Escola localiza-se em uma cidade do litoral cearense, e o trabalho contou com a participação de três professoras polivalentes que desenvolveram um projeto de contação de histórias com duas turmas do $4^{\circ}$ e $5^{\circ}$ ano do Ensino Fundamental, totalizando 125 alunos participantes. As atividades tiveram duração de 2 meses, totalizando 18 encontros entre as partes citadas.

Durante esses dois meses da realização deste trabalho, nesta ação conjunta entre docentes, coordenação e equipe de formação, foi possível o desenvolvimento de atividades que serão relatadas a seguir.

\subsection{Metodologia e Resultados da Experiência}

As turmas puderam trabalhar de modo interdisciplinar e realizaram atividades diversas descritas no quadro abaixo.

\section{Quadro 1: Resumo das atividades realizadas}

\begin{tabular}{|c|}
\hline $\begin{array}{l}\text { Realização de entrevistas breves com familiares e às pessoas próximas dos } \\
\text { lunos a fim de conhecer alguns medos que as pessoas têm ou já tiveram na } \\
\text { ida e quais as alternativas que estas utilizaram para enfrentá-los; com esta } \\
\text { ção, os alunos, além de conhecerem os medos dos adultos, identificaram } \\
\text { s características estruturais de uma entrevista; }\end{array}$ \\
\hline $\begin{array}{l}\text { Registro no editor de texto do laptop educacional das entrevistas } \\
\text { realizadas; }\end{array}$ \\
\hline ução de tabelas e gráficos a partir de coletas de dados da entrevista; \\
\hline $\begin{array}{l}\text { Construção de personagens amedrontadores registrados em um primeiro } \\
\text { momento em uma folha de papel em branco entregue para as duplas de } \\
\text { alunos; }\end{array}$ \\
\hline $\begin{array}{l}\text { Identificação de exemplos de feitiços e poções no filme de Harry Potter } \\
\text { (Ordem da Fênix); }\end{array}$ \\
\hline $\begin{array}{l}\text { Pesquisa na Internet sobre a diferença entre porções, feitiços e } \\
\text { encantamentos; }\end{array}$ \\
\hline ma receita de porção mágica; \\
\hline $\begin{array}{l}\text { ra e escrita das histórias em duplas por meio do } \\
\text { KWORD; }\end{array}$ \\
\hline $\begin{array}{l}\text { Identificação dos elementos que constituem as narrativas construídas, por } \\
\text { meio de aula expositiva pela professora de Português; }\end{array}$ \\
\hline $\begin{array}{l}\text { Trabalho com o vocabulário dos textos por meio das pesquisas realizadas } \\
\text { contos inventados; }\end{array}$ \\
\hline
\end{tabular}


CBIE-LACLO 2015

Anais do XXI Workshop de Informática na Escola (WIE 2015)

Criação de cenários assustadores pelos alunos por meio do aplicativo TUXPAINT no laptop educacional;

Encenação das histórias produzidas, realizada pelos criadores de cada história;

Revisão das histórias elaboradas, realizada pelas professoras, em relação aos aspectos textuais e gramaticais;

Confecção do livro, contendo todas as histórias feitas pelos alunos.

Desse modo, as turmas realizaram atividades diversas: de início, foi pensado como trabalhar com os alunos de modo que houvesse uma direção interdisciplinar, envolvendo texto, desenho dos cenários, tabelas e gráficos. Para tanto, foram necessárias algumas ações combinadas, como instrução aos alunos para conversa com pais e familiares acerca de histórias de terror, pesquisas na Internet, além da participação na contação de histórias com terceiras pessoas do convívio dos alunos.

Na segunda etapa, foi apresentado o projeto para as turmas do $4^{\circ}$ ao $5^{\circ}$ ano e para toda a escola por meio de um mural. Este trazia uma explicação detalhada de como este trabalho seria desenvolvido. Segundo depoimento de uma das professoras envolvidas:

"O mural foi uma maneira de socializar as atividades que vinham sendo
desenvolvidas na escola e assim mostrar aos demais professores, alunos e
pais, que projetos desta natureza, com o uso da tecnologia, podem agregar
valor numa ação pertinente, vinculada ao conteúdo curricular." (Professora
de Português)

A divulgação na escola, por meio deste mural no pátio com o tema do projeto, mostrou-se importante, pois foi uma maneira de socializar a experiência junto à comunidade escolar. Ressaltamos que esta ação trouxe muitos entusiasmos aos alunos.

$\mathrm{Na}$ etapa seguinte, foram realizadas rodas de conversa sobre a premissa "as coragens e medos individuais dos alunos". Ideias sobre os medos e a coragem que todos sentimos foram discutidas e socializadas neste momento. Neste momento, foi trabalhado o conto da Maria Angula ${ }^{1}$, e assim foi possível ampliar o conhecimento dos alunos sobre a existência de outros contos de assombração.

\footnotetext{
${ }^{1}$ Disponível em: http://buhistoriasdemedoecoragem.com.br/mariaangula.pdf
} 
Na sequência, foi entregue à turma uma folha em branco para que cada aluno criasse um personagem amedrontador, detalhando suas características e seu modo de vida, com nome, onde vivia e costumava aparecer, breve descrição e representação gráfica deste personagem e por quais motivos as pessoas se amedrontam diante dele. Este momento foi um dos primeiros passos para envolver os alunos na iniciação da criação dos contos.

Durante a realização desta atividade, os alunos conversaram e trocaram muitas ideias em grupo. Por meio dos desenhos produzidos, foi possível iniciar a criação dos personagens assustadores que iriam compor as narrativas e os cenários. Ainda nessa etapa, as pesquisas na Internet marcariam a introdução das Tecnologias de Informação e Comunicação (TIC) nas ações do projeto. Usando o laptop educacional, em duplas, os alunos pesquisaram sobre os temas Poções, Feitiços e Encantamentos.

Após essa atividade, os novos criadores de contos passaram a utilizar o processador de texto KWORD para descreverem suas pesquisas, bem como registrar as características dos personagens da narrativa da história da Maria Angula.

Em continuação ao trabalho, as turmas assistiram ao filme Harry Potter $^{2}$ ordem da Fênix, que tem em seu enredo temas associados ao conteúdo pesquisado. Logo após sua exibição, os alunos socializaram o que foi identificado de feitiços e porções. Na sequência, a professora de Português apresentou alguns tipos de receitas, porções, encantamentos e feitiços e solicitou aos alunos a criação de um texto coletivo no Google Drive $^{3}$ sobre "porções mágicas". Em paralelo a essa atividade, também fizeram pesquisa na Internet sobre cenários de histórias de assombração.

\footnotetext{
${ }^{2}$ Harry Potter é uma série literária de aventuras fantásticas escritas pela britânica $\underline{\text { J. K. Rowling. É }}$ constituída por sete livros e, desde o lançamento do primeiro volume, Harry Potter e a Pedra Filosofal, em 1997, ganhou grande popularidade e sucesso comercial no mundo todo e deu origem a filmes, videojogos, entre outros itens. ROWLING, J.K. Harry Potter and the Order of the Phoenix. New York: Scholastic, 2003.

${ }^{3}$ O Google Drive é um pacote de aplicativos do Google baseado em AJAX. Alguns dos recursos mais peculiares é a portabilidade de documentos, que permite a edição do mesmo documento por mais de um usuário e o recurso de publicação direta em blog. Ele permite aos usuários criar e editar documentos online ao mesmo tempo, colaborando em tempo real com outros internautas. Os aplicativos permitem a compilação em PDF.
} 
Na etapa seguinte, a turma foi divida em equipe, e cada uma recebeu um conto de assombração para identificação e reconhecimento acerca do lugar onde o conto acontecia. Ao final desta fase, os alunos criaram cenários de histórias de assombração usando o aplicativo TUXPAINT. Entendemos que esse programa, por ser composto de botões grandiosos, texto descritivo e muitas cores, apresenta-se mais vivo e complacente ao público infantil. Sua usabilidade abrange sons diferenciados a partir do manuseio produzido em cada ferramenta. Esse aplicativo oferece ainda a possibilidade de desenho livre, uso de linhas, uso de formas geométricas, além de carimbos, parte daí sua relevância no desenvolvimento de algumas atividades desta experiência. Como atividade de campo, as turmas visitaram a brinquedoteca, espaço do programa "Ceará cresce brincando" " 4 e lá puderam vivenciar outras histórias de assombração de modo que, além de ouvirem as narrativas, puderam analisar o cenário preparado pelas contadoras de história.

Outro momento relevante do projeto consistiu na realização pelos alunos de entrevista com colegas de outras turmas, com pais e parentes próximos para descobrir quais os "medos, medinhos e medões". As perguntas foram elaboradas pelas professoras, sendo explicada para a turma a definição em linhas gerais do que é um roteiro de entrevista. Durante essa etapa, as noções de construção de tabelas e gráficos foram trabalhadas pela professora de matemática para que os alunos pudessem organizar os dados das entrevistas realizadas para a inserção de um painel na sala. Depois, a professora de Português explicou os elementos que formam uma narrativa e solicitou que os alunos identificassem personagens, tempo e cenário da história "A princesa e os pássaros". Em seguida, distribuiu para equipes histórias que causam medo e propôs que os alunos as encenassem.

A seguir, foram formadas duplas de alunos para que estes criassem seus próprios contos usando a premissa sugerida pelas professoras: medos, "medinhos" e coragens, foi indicada a criação de ilustrações e cenários no aplicativo TUXPAINT

\footnotetext{
${ }^{4}$ Disponível em: http://cearacrescebrincando.org

${ }^{5}$ Disponível em: http://buhistoriasdemedoecoragem.com.br/aprincesaeospassaros.pdf
} 
CBIE-LACLO 2015

Anais do XXI Workshop de Informática na Escola (WIE 2015)

cujos textos foram digitados no editor KWORD. Esse programa de editor de textos foi selecionado para o desenvolvimento das atividades por permitir a criação de folhetins, textos ilustrados, textos com fórmulas matemáticas, dentre outras funcionalidades. Este aplicativo possui várias fontes tipográficas (tipos de letras) que tornam os textos mais atraentes e legíveis.

Por fim, os contos criados foram organizados em um livro impresso a ser entregue para alunos, pais, professores e comunidade. Abaixo, apresentamos um trecho do prefácio do livro organizado pela Supervisora Pedagógica e Coordenador Pedagógico da escola:

\footnotetext{
"A criança enriquece o seu repertório na leitura e escrita quando são postas em contato com este mundo imaginário. Este livro tem por finalidade apresentar o produto final do Projeto "ai que medo! Com o laptop também posso me arrepiar". O mesmo contém uma coletânea de textos de histórias que expressão os sentimentos: "Medo e Coragem". contemplando a participação dos alunos dos $4^{\circ}$ e $5^{\circ}$ ano, sobre a orientação das professoras $\underline{A}$ e $\_$da Escola pesquisada. Este livro teve como ferramenta essencial o laptop, onde despertou o prazer da escrita e oportunizou os educandos o acesso as tecnologias (...)"
}

Vale ressaltar, então, que as atividades realizadas abrangem a reflexão que a era digital pode trazer um modo interativo de leitura e o surgimento do leitor virtual que atua de modo simples e criativo com as interfaces digitais.

\section{Considerações Finais}

$\mathrm{O}$ projeto realizado proporcionou aos alunos o contato com diversas histórias e contos de "terror", contados e recriados a partir do uso das tecnologias digitais. Cenários, vídeos, encenações e contos interativos foram vistos pelos participantes, este acesso possibilitou uma sensibilização significativa para o desenvolvimento da criação dos contos.

Por meio das observações, foi possível concluir que as atividades realizadas no decorrer do projeto trouxeram possibilidades mais amplas para a escrita de contos na escola com o uso de recursos digitais, este aspecto pode ser constatado com a construção dos cenários ilustrados e produções elaboradas pelos alunos, com o uso do laptop educacional. Os alunos puderam ler, discutir, visualizar e ter contato com diversas formas de contar e escrever histórias. 
Mencionamos que foi importante para os discentes terem seus escritos publicados em um livro impresso. Esta ação trouxe um incentivo a mais na execução das atividades planejadas pelos alunos, visto que estes puderam perceber um possível reconhecimento diante da comunidade escolar.

Foram vistos outros aspectos relevantes nesta experiência, como planejamento prévio e eficaz acerca do tema trabalhado; o assunto escolhido estava contemplado no currículo das turmas trabalhadas; o envolvimento e a participação da comunidade escolar, professores, pais, alunos de outras séries; e, por fim, o contato e a troca acerca dos temas assombração, medo e coragem, com outros pares, pais e colegas de outras turmas, assim, esta dinâmica possibilitou o fomento à criação das histórias com o uso da tecnologia produzidas ao longo da realização do trabalho.

\section{REFERÊNCIAS}

BUSATTO, C. Contar e encantar: pequenos grandes segredos da narrativa. Petrópolis, RJ: Vozes, 2003. RJ: . A arte de contar histórias no século XXI: tradição e ciberespaço. Petrópolis, Vozes, 2006.

CHARTIER, R. Estudos Históricos, Rio de Janeiro, vol. 7, n. 13, 1994, p. 97-113.

LÉVY, P. Cibercultura. São Paulo: Editora 34 Ltda, 1999.

LIMA, C. da S.; CASTRO, F. de A. Da HQ à animação - o uso de diferentes ferramentas computacionais na prática educativa. XV Workshop de Informática na Escola (WIE 2009).

PERRENOUD, P. “Construir competências é virar as costas aos saberes?" In:

Revista Pátio, Porto Alegre: ARTMED, ano 03, n 11, jan. 2000.

SANTANA, A. L. Contadores de Histórias. In:

http://historiasdafronteira.blogspot.com.br/p/a-importancia-do-contador-dehistorias.html / acesso em 18/2/15

SOBREIRA, R. S. E.; NUNES, C. M.; MORASSI, B. S. Produzindo histórias não lineares: um incentivo à produção escrita e leitura, através do uso contextualizado da tecnologia. II Congresso Brasileiro de Informática na Educação (CBIE 2013). XIX Workshop de Informática na Escola (WIE 2013). DOI: 10.5753/CBIE.WIE.2013 